\title{
Different design approaches to structural fire safety
}

\section{Giuliani, Luisa; Budny, I.}

Published in:

International Journal of Lifecycle Performance Engineering

Publication date:

2013

Document Version

Early version, also known as pre-print

Link back to DTU Orbit

Citation (APA):

Giuliani, L., \& Budny, I. (2013). Different design approaches to structural fire safety. International Journal of Lifecycle Performance Engineering.

\section{General rights}

Copyright and moral rights for the publications made accessible in the public portal are retained by the authors and/or other copyright owners and it is a condition of accessing publications that users recognise and abide by the legal requirements associated with these rights.

- Users may download and print one copy of any publication from the public portal for the purpose of private study or research.

- You may not further distribute the material or use it for any profit-making activity or commercial gain

- You may freely distribute the URL identifying the publication in the public portal

If you believe that this document breaches copyright please contact us providing details, and we will remove access to the work immediately and investigate your claim. 


\section{Different design approaches to structural fire safety}

Abstract: Fire has always been a major threat for buildings and other structures, leading to consequences that can affect both the safety of people and the usage or in some cases the very survival of constructions, due to collapse mechanisms induced by fire or fire effects.

Aim of this paper is to highlight how both safety issues (avoid people injuries and preserve integrity of constructions) are addressed in the framework of current design practice for fire safety of steel constructions. In particular, three distinct approaches are distinguished and applied to the case study of a steel car park: i) design for resistance class; ii) design for fully developed fire; iii) advanced design.

The first two refer to well established procedures proposed by prescriptive regulations, and even if it seem possible to identify different unexpressed safety goals among the two, still it is not easy to a-priori evaluate which design is the safest or the most economical one: a punctual analysis of the different aspects and a comparison of the resulting designs is therefore of interest and is presented in this paper with reference to the case study considered.

The third approach refers instead to a performance-based fire design of the structure (PBFD), where safety goals are explicitly defined and a deeper knowledge of the structural response to fire effects can be achieved, for example with the avail of finite element analyses (FEA). On the other hand, designers can't follow established procedures when undertaking such advanced investigations, which are generally quite complex ones, due to the presence of material degradation and large displacements induced by fire, as well as the possible triggering of local mechanism in the system. An example of advanced investigations for fire design is given in the paper with reference to one frame of the considered car park, outlining the most problematic aspects in the modelling and in the interpretation of the results and making a focus on the collapse mechanisms of steel frames such has catenary action and sway and non-sway collapse.

Keywords: structural fire safety design, resistance class, fully developed fire, performance-based fire design (PBFD), steel car park, nonlinear transient analysis, thermo-plastic material, geometric nonlinearities, collapse mechanism, sway and nonsway collapse.

References to this paper should be made as follows:

Biographical notes:

\section{INTRODUCTION}

As witnessed in several emblematic cases of fire-induced collapses in the past and recent time, fire has always represented a major and relatively frequent hazard for civil constructions. In the following few cases historical buildings fires are briefly reported, with the aim of highlighting this aspect; a more complete list of cases can be found in (COST, 2007) and in (Salleh\&Ahmad, 2009). 
The case of the Italian theatre "La Fenice", in Venice, is one of the most renewed examples of repeated fires: as a matter of fact the theatre was originally named after being reconstructed in consequence of a fire, which burned down a previous theatre at the end of XVIII century. About one century later in 1836, an accidental fire destroyed the theatre, which was quickly reconstructed. Another fire, this time due to arson, destroyed the theatre again in 1996. The theatre was rebuilt and reopened just few years ago, rising again from his ashes, as the story of its name goes.

A similar story has been experienced by another historical building, the Christiansborg Palace in the centre of Copenhagen, built in the half of XXVIII century as residence for the Danish monarch and now house of the Danish Parliament: in 1794 a fire, presumably triggered by a stove, destroyed almost the entire building. A second palace was therefore rebuilt, which caught fire again in 1884 (Fig.1, left), nearly one century after the first fire. Contrarily to the Italian theatre, this particular building did not suffer other fire recently, but other historical building in the same central area of the city did: just a year ago, in May 2010, the Dehn's Palace, which is located just few hundred meters away from the Christiansborg Palace, collapsed as a consequence of a fire that possibly triggered in the roof and spread throughout the building (Fig.1, right). The event reminded the citizens of another fire that just few years earlier, in 1992, had involved the Odd Fellow Palace, another historical building located on the very same street.

[Fig.1: Fires in Copenhagen city centre: Otto Bache's painting of the fire at Christiansborg Palace in 1884 (left) and fire-induced collapse of the Dehn's Palace in 2010 (right)]

Building fires however have not been limited to historical buildings and are as a matter of fact great concern for modern constructions too: in multi-storey buildings for example, despite new materials and fire safety measures, disproportionate collapse can be triggered by a possible vertical spread of the fire. This has been the case of the collapse of the Madrid Windsor tower in 2005 and of the multi-storey building of the Delft University in 2006, just to mention few recent example; a more detailed list of fires in high rise building can be found in (Hall, 2009).

The important lesson that can be learned from those cases of fire-induced collapse is that the usual fire design strategies are not always sufficient for assuring fire safety under all circumstances and even when a safe evacuation has been ensured, major structural damages and collapses could not be always avoided.

Aim of this paper is to highlight how both safety issues (avoid people injuries and preserve integrity of constructions) are addressed in the framework of current design practice for fire safety of steel constructions. In particular, three distinct approaches are distinguished and applied to the case study of a steel car park: i) design for resistance class; ii) design for fully developed fire; iii) advanced design.

[Fig.2: Design approaches to structural fire safety]

\section{DESIGN APPROACHES TO STRUCTURAL FIRE SAFETY}

Fire Safety Engineering has been developed in Europe by the Swedish and English schools, which set the basis for the understanding and the modelling of fire compartments (Magnusson and Thelandersson, 1970; Thomas et al., 1972). Such studies constituted the 
basis for the development of approved fire regulations and fire codes, which forms nowadays the prescriptive approach to fire safety design.

\subsection{Prescriptive approaches to structural fire safety}

The fully-developed fire method (Pettersson et al. 1976) was based on the assumption of a ventilation controlled fire and on the parameter dependency on property of the fuel and of the compartment. The method led to a graphical formulation of temperature-time curves characterized by a heating phase, a peak and a cooling phase.

The element verifications consider the highest temperature reached by the steel under the whole developing of the fire, so that it can be said that the general idea of fire compartment design consists in the prevention of any failure in the structure during the whole development of a fire that can trigger in a given compartment (Fig.2b).

Further studies based on the same approach led to develop other parametric curves described by analytical expressions. This is the case of the fire curves reported in the Eurocodes, which present a monotonically increasing temperature in the heating phase and a linear cooling phase (Wickström, 1985). A unique expression for a fully developed fire proposed by (Hertz, 2005) is reported in the Danish code (DS410, 1998) and in the Danish national annex of the Eurocodes (EN1991-1-2 DK NA, 2007).

Even if parametric curves are a quite realistic modelling of the fire action, some uncertainties maybe present in the knowledge of compartment and fuel properties and in the main assumptions adopted for the analytical description of the compartment fire. In many countries therefore, conventional temperature-time curves are mostly adopted for the structural fire design instead of a more realistic modelling of the fire. Nominal curves are not meant to model the fire action in a realistic way but are aimed at providing a conventional curve for describing the gas temperature. These curves are as an intention very severe ones; the standard fire ISO 834 for example has been obtained has interpolation of many different natural fires, in order to lead to a conservative design of the elements (ISO834-1, 1975). When standard fire is used, the fire action does not depend on the actual fire load or on the properties of the compartment and the temperature increases monotonically with the time without any cooling phase. As a consequence, the resistance of structural elements has to be referred to a specific and limited time of the fire, depending on a certain class of resistance defined for the elements (Fig.2a). Ideally, the resistance classes should be somehow related to the evacuation time required for the specific premises. Of course, other parameters but the structural stability such as smoke and toxicity affect significantly the egress time and the number of injuries and casualties; furthermore, evacuation times are very difficult to assess and very different resistance classes are required in different European countries for the same types of construction, as highlighted in the following. The safety of people however appears as the main goal of this design approach, whereas the behaviour of the structure after that time remains undefined.

The possibility of reusing the structure after the fire or undergoing limited repair is however an important issue too, especially in the framework of sustainability of civil constructions (Shipp, 2007; Torero, 2011). Furthermore, the possibility of a collapse represents a danger for people even after the building evacuation, for example in case of an outwards (sway) collapse of the system. 


\subsection{Performance-Based Fire Design (PBFD)}

Standard verifications carried on single elements don't allow following the propagation of the failures and outlining such collapse modalities. More advanced investigations are required to this aim, which typically avail computational fluid dynamics (CFD) programs for a more realistic assessment of the fire action, as well as finite elements (FE) codes for the modelling of the structural response.

In this respect, a performance-based approach to fire safety design can be followed, by defining a set of safety and performance goals: for example, the structure could be designed in such a way, to withstand undamaged a certain time of fire, but also to prevent the propagation of failures and avoid a collapse after that time span or under circumstances that are more critical than the design fire: even in case the structural elements are designed for resisting a compartment fire without failing, unexpected critical events may lead to an underestimation of the actual fuel load (e.g.: arson, misuse of the structure) or to an overestimation of the structural capacity (e.g. human errors in the design or execution phases of the construction); other critical situations could be triggered by the unfortunate occurrence of errors or defects (Bontempi and Petrini, 2010), which are not critical for the structure when triggering one at a time, but may not be absorbed within the usual safety coefficients in case of simultaneous occurrence with a fire; finally, fire can also occur as a consequence of other critical events such as an earthquake or an explosion (Wald et al., 2002): in this case the fire would affect a structure already partially damaged, leading most likely to consequences greater than expected.

The aforementioned critical circumstances are not contemplated in the usual design requirements, being economically unfeasible to design a structure that can withstand all those unexpected and rare events without any damage. Nevertheless, the property of structural integrity, intended as the ability of the structure to withstand accidental circumstances without suffering damages disproportionate to the original event (ASCE 702,2002 ), is nowadays considered an essential safety requirements by most regulations in Europe and in US (UFC 4-023-03:2005; EN1991-1-7:2006) and within the engineering community as well. Therefore, even if local damages and failure can be accepted in case of very critical events, the possibility of a major collapse should be avoided under all circumstances.

PBFD lend itself to be effectively used to this aim: however, due to the lack of a wellestablished methodology and the complexity of this kind of investigations, where material degradation, large displacements and local mechanisms should be accounted for, the performance-based approach to structural fire safety have been hardly used in the daily practice and is mostly limited to research studies or design of special constructions.

In this paper the main steps of PBFD are discussed and exemplified by investigating the collapse mechanisms of a simple steel structure. Particular attention is devoted to methodological aspects such as modelling of uncertainties and definition of the collapse criteria. Finally the outcomes of the investigations are compared with the results of the two aforementioned prescriptive design approaches, carried on single elements of the same structures by using standard and fully-developed fires. 


\section{DESIGN OF AN OPEN STEEL CAR PARK}

The structure taken as a case study is an open steel car park (Fig.3, left), built in France in 2000 , in order to perform real fire tests on unprotected steel construction (Joeux et al., 2001) and extensively studied in literature (Pustorino et al., 2008; Crosti, 2009).

[Fig.3: Photo of the car park (left) and a sketch of its structural system (right)]

The structure is $15 \mathrm{~m}$ wide, $32 \mathrm{~m}$ long and $3 \mathrm{~m}$ high, with a total floor surface of 480 $\mathrm{m}^{2}$. The structural system (Fig. 3, right) is composed by the S235 hinged steel elements, which support a composite floor slab, formed by a corrugated steel plate and a concrete slab of $12 \mathrm{~cm}$ height.

The three aforementioned design approaches are applied to this structure and the outcomes are compared, making a focus on the main differences and on their influences on the resulting designs.

\subsection{Prescriptive design of the steel car park}

Fire modelling: choice and assumption

The following fire models, also reported on the left side of Fig.4, have been considered for the purpose of the car-park investigation:

a. standard fire curve with consideration of $60 \mathrm{~min}$ resistance class (R60);

b. parametric fire curve according to the Swedish method (Petterson\&al., 1976), based on the assumption of a ventilation controlled fire with a heating phase, a peak and a cooling phase;

c. parametric fire curve presented in the Eurocodes (EN1991-1-2: 2004), representing either ventilation or fuel controlled fire and characterized by a monotonically increasing temperature in the heating phase and a linear cooling phase (Wickström, 1985);

d. parametric fire curve reported in the Danish Standard (DS 410:1998) and in the Danish national annex of the Eurocodes (EN1993-1-2 DK NA: 2007).

[Fig.4: Considered fire models (right) and effect of different assumption on the fire curves (right)]

With respect to the standard fire, a central role is played by the required time of fire resistance, since the assumption of different resistance classes clearly lead to very different resulting designs. Resistance classes are usually calibrated on the basis of the type and usage of the structures; however, being defined at a national level, the required resistance time for the same construction varies strongly among distinct European countries, as shown in Tab.1 with respect to the case of car parks (Pustorino et al., 2006).

With respect to the three parametric fires, a fire load density of $q_{t, d}=300 \mathrm{MJ} / \mathrm{m}^{2}$ (per unit of enclosing surface) has been considered for the car park. This value is recommended as conventional fire load density to be assumed for parking place in (Hertz, 2005 ) and is also consistent with the calculations carried on this specific structure (worst case scenario) and reported in Tab.2. The open car park has been considered as a single compartment of total enclosing area $A_{t}=1242 \mathrm{~m}^{2}$ and the missing vertical walls have been treated as openings of area $A_{v}=282 \mathrm{~m}^{2}$ and height $h_{e q}=3 \mathrm{~m}$, leading to an actual opening factor $\mathrm{O}=0.39 \mathrm{~m}^{1 / 2}$. This value is eventually reduced, as the prescriptive fire regulations impose different limits on the maximum value of this parameter, as reported in Tab.3. 
Besides the choice of the fire curve, other assumptions and parameters affect the design according to the different format considered.

With reference to the Eurocodes parametric fires, significant differences can be observed in the resulting curves, depending on the type of cars considered and the associated rate of fire growth: in this case particularly a medium instead of a fast rate of fire growth, which is obtained if old car model are considered, leads to a fuel controlled fire, which is significantly less severe than the ventilation controlled fire obtained with a fast growth rate of fire growth (recent car models).

It's worth noting that, in this particular structure, an important parameter that is governing the resulting temperature-time curves is the limitation on the maximum opening factor value prescribed by the Eurocodes, which is responsible of the apparently not consistent modelling of the fire in an open compartment as a ventilation-controlled one. The limit on the opening factor is also affecting the Danish fully developed fire curve: the expression of the curve is the same in the Danish Standard as well as in the national annex of the Eurocodes, but the imposed limits on the opening factor of 0.3 required by the first code was not maintained in the national annex, leading to shorter and often globally less severe fire curves than those considered for the design of same structure according to the old regulation (Fig.4 left). The differences in the values to be used for the opening factor, as well as for other properties of the fire and of the compartment such as thermal inertia and fire load density are reported in Tab.3, where the acronym EN and DS are used for the Eurocodes Danish Standards prescription respectively.

[Tab.1: Resistance classes for open-car parks in European countries (Pustorino et al., 2006)]

[Tab.2: Design fire load densities under different scenarios]

[Tab.3: Values of relevant parameters defined in the Eurocodes and in the Danish National Annex]

\section{Structural design: differences and effects}

Distinct design procedures have been considered for the design of the structural elements, consistently with the assumption of the different fire modelling and particularly: i) the Swedish method as reported in (Pettersson et al., 1976) has been used for the case of the Swedish parametric fire; ii) the Danish National Annex (EN1993-1-2 DK NA: 2007) has been taken as reference for the design with the Danish curve; iii) the Eurocodes design procedures as reported in (EN1993-1-2: 2005) have been followed for both the cases of parametric fire with linear cooling and standard fire.

Some relevant differences can be found among the considered design procedures, which, due to the counterpoising effects on the final design, don't allow for an a-priori evaluation of the safest or the most economical one: a punctual analysis of the different aspects and a comparison of the resulting design is therefore of interest. In this respect, the following aspects seem worth to be highlighted:

1. Maximum temperature: all the parametric curves reach higher maximum temperatures than the standard fire (Fig.4, left). However, the steel heating curves are influenced also by the duration of the fire, which is instead longer for the standard fire, so that it can be difficult to assess which fire modelling leads to the highest temperatures in the steel elements. 
2. Cooling phase: the presence of a cooling phase determines a delay between the time of maximum fire and steel temperatures, depending on the thermal resistance of the section. By increasing the amount of the insulation for example, the delay time will increase too and the fire and heating curves will intersect at a lower point. On the contrary, when the standard fire is used, the time the verifications refer to is always the same (in this case $60 \mathrm{~min}$ ) and does not depend on the section or on the insulation.

3. Steel resistance: at high temperatures, the stress-strain curve of steel doesn't show a well defined yielding point and a distinction between the elastic limit and the ultimate resistance has to be done. In the Eurocodes (EN1993-1-2:2005) the 2.0\% stress is considered for the verifications and referred to as effective yield $f_{y}$, while in the Swedish method and in the Danish National Annex the use of a stress corresponding to a residual strain of $0.2 \%$, referred in the following as proof stress and indicated as $f_{y, 0.2}$, is prescribed for fire verifications. The stress calculated at $2.0 \%$ of deformation corresponds to the ultimate resistance under all temperatures, while the $0.2 \%$ proof stress is closer to the elastic limit of the steel. One major consequence of the choice of $0.2 \%$ resistance consists in the fact that it degrades more than the steel stiffness (up to ca. $580^{\circ} \mathrm{C}$ ), so that the failure modality of non-slender columns won't change to buckling failure during a fire.

4. Load safety factor: a significant discrepancy concerning the reduction of the actions in case of fire is found among the procedures prescribed by European and Scandinavian regulations. In the above mentioned Danish National Annex, even if the load safety coefficients for the ULS combinations are less severe than those used in other countries, the load reduction in case of ALS is on the other side smaller, as can be seen in Tab.4: in the top part of the table, the safety coefficients to be used in the two above mentioned load combinations are reported, while in the bottom part of the table the resulting loads are calculated and compared for the case of loads acting on the floor slab of the considered car park.

5. Verification level: the level of structural verifications is particularly important in case of fire design, since it affects the possibility and the extent of acceptable damage and the consideration of thermally induced eigenstresses in the elements. From a general point of view, structural verifications can be performed at: i) fibre, ii) sectional, iii) element, or iv) structural level.

For example, in the service limit state (SLS) the crisis of a single point of a section (i.e. of a fibre of the element) determines the failure of the verification, while in the ultimate limit state (ULS), solicitations at a sectional level are checked against resistant sectional forces. The resistance domain is bigger in case of ULS than SLS (i.e. less conservative verifications), which is justified by the lower occurrence of ultimate loads with respect to the service conditions.

In the accidental limit state (ALS) a further relaxation of the verification level could be considered, by checking that the soliciting load is lower than the one that would trigger a mechanism in the element (according to the limit analysis procedure) or the one that would determine a maximum displacement exceeding a predetermined value. The latter is what considered in Swedish method (Pettersson et al., 1976) with respect to the beam verification, where a maximum displacement $\delta_{\text {cr }}=\mathrm{L}^{2} /(800 \mathrm{~h})$ is considered as failure criterion. For the verification of columns instead, the explicit consideration of eigenstresses induced by the hindered thermal expansion requires to consider the effects that the rest of the structure has on the element (structural level). The use of different verification levels in the Swedish method however could be only 
partially reflected in the design of this specific structure, which presents hinged connections between the elements: as a consequence, the beams don't benefit the plastic redistribution along the element length and the columns don't suffer from hindered thermal expansion. With respect to the first aspect however, the influence of the type of load distribution for the Swedish method can be observed in Tab.6: the difference in the insulation thickness required for beam $\mathrm{B}$ with respect to beams $\mathrm{C}$ and $\mathrm{D}$ is mainly due to the different load distribution, which is a uniform distributed load for the first one and a mid-span pointed load for the latter ones.

Tab.4: Differences in safety factors for design values of actions (top) and reduction of the actions in case of ALS with reference to a floor slab of the car park (bottom).

\section{Critical temperatures and insulation design}

The maximum steel temperatures of beams and columns obtained for the different fire curves are reported in Tab.5 together with the critical temperatures calculated accordingly to the different design procedures. It can be observed that, as a direct consequence of point 1), temperatures reached by the steel elements are higher when the parametric fires are used. Furthermore, the critical temperatures of the elements are lower with respect to the Danish and Swedish parametric fires, due to what explained in point 3) and 4). For the considered structures, it can be therefore stated that the procedure in compliance with Scandinavian regulations preserves a higher safety level referring to the unprotected steel elements, i.e. the verifications of the elements of the steel car park are more severe.

When referring to the design of the insulation however, a lower amount of insulation is required when the parametric fire design is considered, as shown in Tab.6. This apparently inconsistent result is due to the greater effect that the insulation plays in the fully developed fire design approach, due to what explained in point 2):the effect of the insulation in case of a parametric fire not only reduce directly the temperature of the steel at a certain time, but also delays the heating of the elements, so that the maximum steel temperature is reached at a later stage, when the fire temperature is lower, which also indirectly affects the steel design temperature, as better shown in Fig.5.

[Tab.5: Maximum and critical steel temperature of the car-park elements $\left({ }^{\circ} \mathrm{C}\right)$ ]

[Tab.6: Necessary insulation layer (mm of thickness for each element and total amount in $\mathrm{kg}$ )]

[Fig.5: Heating curve of a steel element for standard and EN parametric fire]

\subsection{PBFD approach for the design of a car park frame}

The central three-span main frame of the car-park taken a case study in the previous section is used as a reference in the following investigations. The frame consists of hinged connected components ordering the brace elements to provide the overall lateral stability of the structure. It is composed by three IPE500 beams, 4 HEB200 columns and two HEM100 braces.

\section{Main steps of PBFD investigation}

The main steps to be followed when performing advanced investigations for PBFD are summarized in the following: 
1. Fire scenarios: the investigation includes two distinct fire scenarios, which are represented in Fig.6. In both cases the standard fire has been considered as thermal action and the steel temperatures have been calculated under the assumption of uniform element temperature as indicated in (EN1193-1-2:2005) and applied to the nodes of the beam directly exposed to the fire; the columns have been instead considered insulated and not directly involved in the fire, in order to better highlight possible collapse mechanism triggered only by the a beam failure.

2. Failure criteria: since the investigations take into account the response of a relevant substructure of the car park, it seems sensible to define the failure criterion at a structural level, by imposing a limit on the maximum displacement of nodal points, i.e. the mid-span of the beam involved in the fire has been monitored in this case. Within the framework of a PBD view, the value for this limit displacement has to be defined depending on safety and performance objectives of the design, which can be limited to the avoidance of a major collapse or also limit the extent of local damage, in order to ensure the possibility of reusing the structure after some repair. In the following, two different limits have been considered, which are reported in Eq. 1 and can be found respectively in (Pettersson et al., 1976) and in (BS5950, 1990).

$$
\begin{aligned}
& \text { Swedish limit: } \quad \delta_{\max }=\mathrm{L}^{2} /(800 \mathrm{H}) \\
& \text { British limit: } \delta_{\max }=\mathrm{L} / 20 \\
& \text {, with L span length of the beam }
\end{aligned}
$$

3. Structural model: a proper material definition for fire investigation should include the change of mechanical and thermal properties with the temperature as well as an accurate representation of stress-strain relationship at elevated temperature. In the investigation performed a bilinear material model with isotropic hardening of $0.3 \%$ has been used. The thermo-plastic behaviour is such that both the stiffness and the ultimate resistance (effective yielding) are a function of the temperature, as indicated in (EN1193-1-2:2005).

Particular attention has been devoted to modelling aspects such as the choice of the finite element types and the calibration of the mesh, in order to ensure the objectivity of the solution. Particularly, due to the significant deformation exploited by steel structures in fire and to the need of highlighting failure mechanism such as buckling and catenary effect, a full large displacement formulation have been used for the investigation.

4. Analysis: the investigation of the frame has been performed considering two separate load step analysis: in the first load step, a static analysis is performed where only vertical loads are considered on the structure at room temperature, while in the second load step, the temperature histories are applied to the nodes of the considered beam and nonlinear transient analysis is carried out.

5. Results: The time resistance of the frame has been then evaluated as the time corresponding to the achievement of the two considered displacement limits. It can be noticed that, due to the fact that the runaway of the beam occurs before the displacements defined by the limitation values are reached, no significant differences appear in the critical temperature imposed by both failure criteria.

\section{Results and comparison with prescriptive design}

The deformed configurations of the frame can be observed in the top part of Fig. 6 with respect to the two considered fire scenarios. The temperature-displacement curves of the 
monitored mid-span node in the two cases are instead reported in Fig.6), where the above mentioned Swedish and British limits are outlined.

The resulting resistance time are reported in Tab.7 and compared with verifications performed in compliance with the prescriptive regulations for the same steel frame and presented in the previous section. A good conformity with the two design approach is shown, which can be imputed to the simplicity of the structural system, which, due to low connection levels between elements is not particularly sensible to thermally induced eigenstresses and lend itself to the single element design, as previously discussed. The same low redundancy of the structural system is responsible of the relatively low fire resistance of the frame, which can't avail the beneficial effect of stress redistribution and catenary action. Furthermore, the 2-dimensional analysis does not include the influence of the other adjacent elements in the perpendicular direction, like the secondary beams and the concrete slab, which could possibly partially increase the grade of horizontal restraint and the fire resistance.

[Fig.6: Deformed configuration of the hinged frame under the assumption of two different fire scenarios: fire in the central (left) and side span (right)]

[Tab.7: Comparison of the outcomes obtained by the prescriptive and PB investigations]

\section{Measures for increased fire resistance}

Referring to the effect of higher degree of horizontal restraints in case of fire, it is expected to improve the frame performance by introducing rigid connections between the structural elements, which were instead constrained by hinges in the original frame.

The new frame structure is investigated with reference to the previous two fire scenarios. For the sake of simplicity and in order to distinguish the investigations on the framed solution from those performed on the hinged one, the fire scenarios on the framed structure are referred to as fire scenario 3 and 4 in the following graphs.

The evolution of the vertical mid-span displacement of the beams involved in fire in the framed solution is reported in Fig.7 together with the curve obtained for the hinged frame and the resistance time is compared in Tab. 8 with that one obtained for the hinged solution. It can be observed that the frame characterized by the rigid connections between the elements is able to sustain a $20 \%$ larger critical temperature than the hinged one, what corresponds to $40 \%$ longer time resistance in this particular case (Tab.8).

This benefit is owed to the moment redistribution along the element span and especially to the higher restrain grade provided by the framed column to the horizontal displacement of the beam. Furthermore, when the vertical displacement of the beam becomes large, the initial compression of the heated beam is gradually lost and at a certain point tension stresses develop in the beam which is forced to elongate due to large deflection and resistance to movement of its end points, provided by the higher horizontal restrain grade of the system. This effect, known as catenary action, leads to a recover of stiffness visible in the change of the displacement slope after the runaway in Fig. 8.

[Fig.7: Deformed configuration of the continuous frame under the assumption of two different fire scenarios: fire in the central (left) and side span (right)]

[Fig.8: Horizontal displacement of the beam end (left) and vertical displacements of beam mid-span for the two cases of fire in the central and side span for the hinged (scenario q and 2) and framed structure (scenario 3 and 4)] 
[Tab.8: Resistance properties of the two separate design solutions of the frame structure]

\section{Modality of the collapse: sway and non-sway collapse}

The investigations performed on the considered frames, irrespectively to the expected fire scenario or the design solution, have evidenced a non-sway collapse mode, i.e. an inward collapse of the structure. This kind of collapse modality can be considered more favourable then a sway-collapse, where the collapsing sections are moving towards outside and can cause damages to adjacent buildings endanger the safety of people outside the premises.

The important aspects concern the circumstances under which a specific mode of failure occurs for a given structure. In general, the predominance of horizontal expansion over the material degradation results in a sway collapse, while the predominance of vertical displacement may induce a non-sway collapse instead (Gentili et al., 2010). Which of the two displacements is the leading one depends on geometrical and static properties of the structural system.

In the three-span frame previously investigated, the heated beam has a moderate length and experience a limited outward expansion. When the temperature increases and causes significant material degradation, the beam end are called back by the high vertical deflection and have time to get overtake their initial position before the vertical runaway of the mid-span, leading to a non-sway collapse of the frame. This happens when the central beam is heated (scenario 1 and 3), but is also visible in case the side beam is the heated one (scenario 2 and 4 ).

Other steel frames however, may have a completely different behaviour. This is the case for example of the pitched-roof portal represented in Fig.9 and investigated in (EUR 24222). This structural typology is mostly used for industrial buildings and has been extensively studied in literature (Song et al., 2007) also with respect to the failure modality (Moss et al., 2009).

Due to the particular inclined configuration and length of the rafters of the two-span portal, the vertical displacement of the mid-span remains instead limited up to the snapthrough of the arch (Song et al., 2009), allowing for a significant outward displacement, due to the arch push and the thermal expansion, which can be considered to cause the collapse of the structure. The sway collapse of the portal is described in (Gentili et al. 2010) and observable in Fig.9.

[Fig.9: Collapse modality of a two-span steel portal (Gentili et al., 2010)]

By the comparison of the two structures, some parameters seem to play a role in the determination of the failure modality, and particularly:

- the shape of the beams

- the grade of horizontal restrain of the beams (i.e. the shape of the frame, the ground restrain of the column and the length and section of the columns)

- the length and the section of the beam

In order to investigate their effect, the rigidly connected car park frame with fire on the side beam (scenario 4) has further been investigated, by varying the length and the section of the beams and columns. The results of the investigation are reported in Fig.10, where the modality of failure is reported in a matrix, where beam lengths vary along the rows while the beam sections vary along the columns. 
As observable in the figure, by increasing the length of the beam or reducing the section of the beam, the failure modality moves towards a sway collapse, i.e. the both factors have an unfavourable effect on the collapse modality of the frame.

Increasing the length or reducing the section of the columns instead has a favourable effect: the light gray area of the matrix in the figure represents the combination of beam length and sections, which gives a non-sway collapse for the original section and height of the columns (HEB200,3m). If the column length is increased to $5 \mathrm{~m}$, the area of the non-sway collapse increases too, comprehending also the dark grey area in the matrix. A similar, even if not equal result is obtained, if the section of the column is reduced, instead of increasing the height.

[Fig.10: Parametric study on the collapse modality of a three-span steel portal]

\section{CONCLUSIONS}

The levels of safety required by regulations and by societal consensus against natural or malevolent events depend on the risk associated to the related action. In case of fire action, the risk is high because of the severe consequences in term of possible casualties and economic losses, which a fire can lead to. However, the occurrence of fire in buildings and other civil constructions is quite difficult to be assessed and also varies significantly with times and geographical areas. In addition to that, the perceived risk, which may differ from the actual one, is even more variable among different countries and cultures, which can serve as an explanation for the different approaches and underlying safety levels followed for the fire design.

To better explain what said above, a reference to the regulation in force in Europe can be useful: in the Eurocodes a distinct design situation is foreseen for seismic action, whereas fire is considered within the accidental design situations among impacts, malevolent explosions, arsons and other exceptional events (EN1990:2001). This reflects the concern of the southern part of Europe, which is a very seismic area (particularly all the Mediterranean regions: Italy, Greece and other Balkans countries, Romania and limitedly Spain). Necessarily, economic interests and research studies in those countries have been mostly focused on seismic events. As a consequence, strong competencies and engineering solutions have been developed in the field of seismic design, whereas the most common design approach for structural fire safety is a simplified one, which relies on the use of nominal fire curves and the definition of a prescribed time of resistance for the structural elements. The compliance with the prescribed resistance classes is a precondition for ensuring a safe evacuation of the building, while no explicit requirements on the serviceability of possibility of reuse of the structure are formulated, as a consequence of the rare occurrence of the event.

In northern Europe instead, and in Scandinavia particularly, buildings have been traditionally built or furnished with wood, while very few major seismic events have occurred $^{1}$ : fire therefore has been always perceived as the main hazard for buildings and research and education in fire safety have been developed as a separate engineering

\footnotetext{
${ }^{1}$ the last one being the earthquake of magnitude 6.2 (Richter scale) that occurred few month ago in the Norwegian volcanic island of Jan Mayen: the island is however mostly inhabited and no casualties were reported, according to the newspapers.
} 
discipline since the '60ies (Drysdale, 2010). The Scandinavian approach to fire safety design is strongly bound to parametric fires, which is a more realistic (and therefore not necessarily conservative) description of the fire action. On the other hand, by relating the fire to the properties of the compartment, the use of parametric fires deny the character of exceptionality of the fire event, and set it among other ordinary loads, with this term meaning actions such as live loads or wind, whose value can be assessed with reasonable reliability in the design. For this kind of action, it seems sensible to maintain a higher safety level and avoid not only casualties and major collapse of the structural system, but also excessive costs derived by repairing and inoperability of the premises. Hence the use of a more conservative strength value for the resistance of steel, the explicit considerations of eigenstresses in the column verification and the assumption of a lower displacement limit as failure criteria for beams, as better discussed in the previous section.

A separate discussion has to be devoted to the PBFD approach, which allows for a deeper understanding of the structural behaviour and possibly for more flexible and effective solutions. For example, the response of a steel structure to fire can be improved without necessarily resorting insulating materials, which are often not durable and quite expensive (Green et al., 2003) by directly modifying the structural system, as shown in the simple example presented above.

Even if the dichotomy between a more realistic modelling and a more conservative design is not solved, the PBFD could be in principle be used with the aim of achieving a safer and not only more economical design. In the framework of a comprehensive approach to the structural integrity and the sustainability of the construction, subsequent safety levels could be considered as performance objectives, depending on the exceptional or accidental nature of the action: with respect to fire, it seems sensible for example to distinguish between arson and compartment fire and require higher safety levels for the latter, which is not only probably more frequent in term of occurrence, but can also be easily quantified depending on the compartment properties.

The definition of performance objectives however is still a crucial point in all kind of performance based design approaches, since it leaves to designer and the contractors the authority of deciding on the safety levels of the construction. Furthermore, due to the absence of procedures easy to be verified, it may pose some problems for the attribution of responsibilities in the unfortunate case of a structural collapse or of an unsatisfactory performance of the construction. In this framework, a general overview of the developing and of fire design and of the main safety goals has been presented in this paper.

\section{REFERENCES}

ASCE 7-02: "Minimum design loads for buildings and other structures", American Society of Civil Engineers, Reston, VA, 2002

Bontempi F., Petrini F.: "Fire-Induced Collapses in Structures: Basis of the Analysis and Design", keynote lecture at the $4^{\text {th }}$ International conference on Structural Engineering, Mechanics and Computation (SEMC'10), Cape Town, South Africa, September 2010

BS5950: "Structural use of steelwork in buildings, Part 8: Code of practice for fire resistance design", British Standards Institution, London, 1990.

COST Action C17: "Built Heritage: Fire Loss to Historic Buildings". Final Report - Part 2, Ed. I. Maxwell OBE, Historic ScotlandC Crown copyright, ISBN 978190496653 1, Edinburgh 2007 
Crosti C.: "Structural analysis of steel structures under fire loading", Acta Polytechnica, Vol.49, No. $1 / 2009$.

Drysdale D: "The origin of fire safety engineering in the UK", FIRESEAT2010, Edinburg, UK, 10 Nov, 2010

DS 410: 1998: "Norm for last på konstruktioner, Danish Standard Association”, 1998 (in Danish).

EN1990: 2001: "Eurocode: Basis of structural design”, July 2001

EN1991-1-2:2004: "General actions - Actions on structures exposed to fire”, October 2004.

EN1991-1-7: 2006: “General actions - Accidental actions", Comité Européen de Normalisation (CEN).

EN1993-1-2:2005: "Design of steel structures - Part 1-2: General rules - Structural fire design"

EN1993-1-2 DK NA: 2007: "National Annex to Eurocode 3: Design of steel structures - Part 1-2: General rules - Structural fire design", 2007

EUR 24222: "Fire safety of industrial halls - A valorization project", Final report, Research fund for coal and steel publications (RFCS), Luxembourg, 2007

Gentili F., Crosti C., Giuliani L. "Performance based investiga-tions of structural systems under fire", $4^{\text {th }}$ International Conference on Structural Engineering, Mechanics and Computation (SEMC' 10). Cape Town, South Africa, 2010

Green M., Butterworth N.A., Burgess I.W., Plank, R.J.: "'Practical Case Studies in PerformanceBased Structural Fire Engineering Design”, ASCE Specialty conference: Designing Structures for Fire, Baltimore, October 2003

Hall J. R.: "High-rise building fires", National Fire Protection Association, Fire Analysis and Research Division, 2009

Hertz K.D.: Assessment of Performance-Based Requirements for Structural Design, proc. of the 8th International Symposium on Fire Safety Science (IAFSS05), Beijing, China, September 2005

DS410: "Norm for last på konstruktioner", Danish Standard Association, 1998 (in Danish)

ISO 834-1:1999: "Fire resistance tests - Elements of building construction - Part 1: General requirements for fire resistance testing", International Organization for Standardization, 1975.

Joeux D., Kruppa J., Cajot L., Schleich S.J., Van De Ler P., Twilt L.: "Demonstration of real fire tests in car parks and high buildings." Technical Report, CTCIM, 2001.

Magnusson S. E., Thelandersson, S.: "Temperature-time curves for the complete process of fire development - A theoretical study of wood fuels in enclosed spaces", Acta Polytechnica Scandinavica, Stockholm, Sweden, 1970

Moss P.J., Dhakal R.P., Bong M.W, Buchanan A.H.: "Design of steel portal frame buildings for fire safety", Journal of Constructional Steel Research 65, 1216-1224, 2009

Pettersson O., Magnusson S.E., Thor J.: "Fire Engineering design of steel structures", Bulletin 52, Sweden, 1976

Pustorino S., Princi P., Giomi G., Cirillo V.: "Regola tecnica prescrittiva - Resistenza al fuoco richiesta agli edifici in base alla destinazione d'uso" Interim Report n. 2, Commissione per la sicurezza delle costruzioni in acciaio in caso di incendio, Luglio 2006 (in Italian, http://www.promozioneacciaio.it/documenti pdf/fuoco/rtp.pdf - last accessed in April 2011)

Pustorino S., Princi P., Nigro E., Ferraro A., Cirillo V.:, "Approccio ingegneristico per la sicurezza strutturale in condizioni di incendio: il caso delle autorimesse fuori terra in acciaio", proc. of the workshop Handling Exceptions in Structural Engineering (HE08), Rome, Italy, November 2008 (in Italian)

Salleh N.H., Ahmad A.G.: "Fire safety management in heritage buildings: the current scenario in Malaysia", proc. of the $22^{\text {nd }}$ CIPA Symposium, Kyoto, Japan October 11-15, 2009

Shipp M.: "Fire as a sustainability issue", Constructing the future, BRE magazine, Issue 31, spring 2007 (http://www.bre.co.uk/pdf/ctf/CTF_31.pdf, last visited April 2011) 
Song Y., Huang Z, Burgess I., Plank R.: "The Design of Pitched-Roof Steel Portal Frames Against Fire, $5^{\text {th }}$ International Conference on Advances in Steel Structures (ICASS07), National University of Singapore, India, 5-7 December 2007

Song Y., Huang Z, Burgess I., Plank R.: "A new design method for industrial portal frames in Fire", proc. of the international conference Application of Structural Fire Engineering (ASFE), Prague, Czech Republic, 19-20 February 2009

Torero J.: "The Twin Towers: 10 years - 10 lessons on sustainable infrastructure", lecture at the Royal Academy of Engineering and The Royal Society of Edinburgh, Scotland, UK, 14 March 2011 (http://www.royalsoced.org.uk/events/reports/2011, last visited on April 2011)

UFC 4-023-03: "Design of Buildings to resist progressive collapse", Unified Facilities Criteria" (UFC), 25 January 2005

Wald F., Bosiljkov V., Da Silva L., De Matteis G., Haller P., Santiago A., Vila Real P.: "Structural integrity of buildings under exceptional fire", proc. of the $1^{\text {st }}$ Cost C12 Seminar, Lisbon 18-19 April 2002 (http://hdl.handle.net/10068/337459)

Wickström U.: "Application of the standard fire curve for expressing natural fires for design purposes", Fire Safety: Science and Engineering, American Society for Testing and Materials (ASTM), STP 882, Harmathy Ed., Philadelphia, 1985 

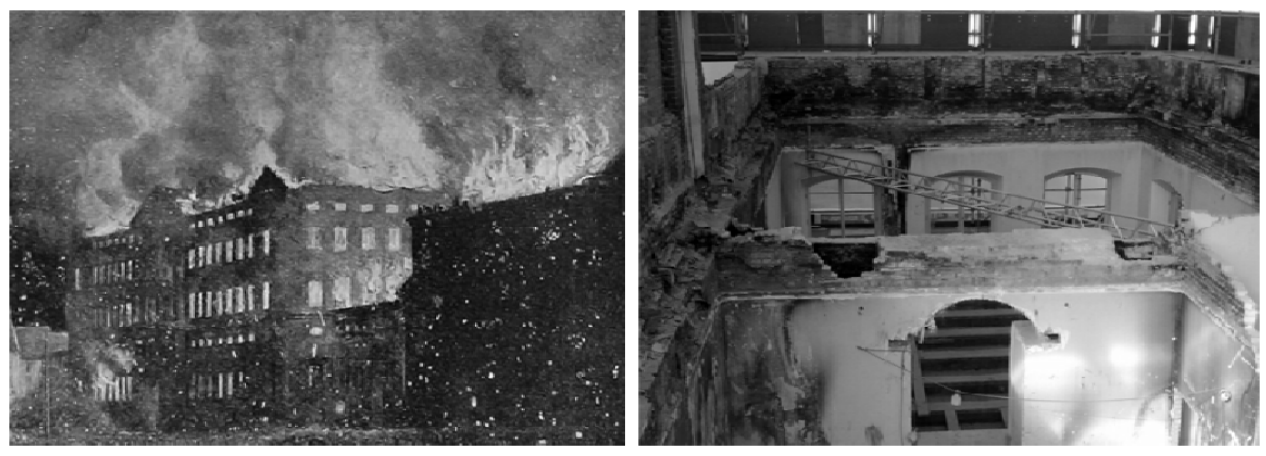

Fig. 1: Fires in Copenhagen city centre: Otto Bache's painting of the fire at Christiansborg Palace in 1884 (left) and fire-induced collapse of the Dehn's Palace in 2010 (right) ${ }^{2}$

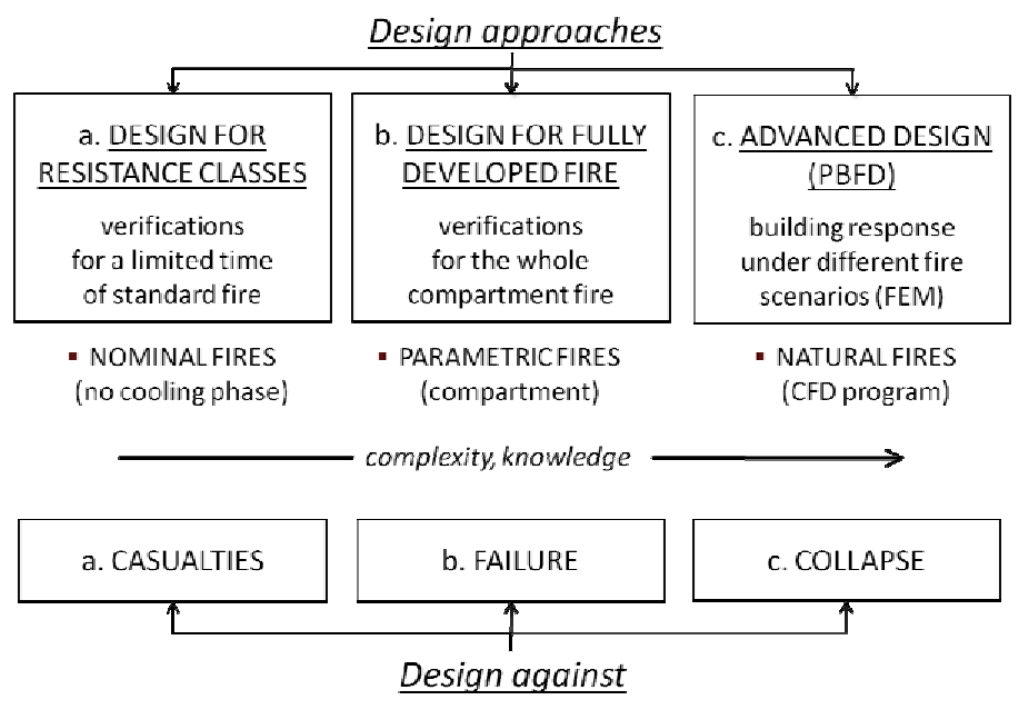

Fig. 2: Design approaches to structural fire safety

2 The left picture, originally published by the magazine "Før og Nu" in 1916, can be found at: http://commons.wikimedia.org/wiki/File:Christiansborgs-brand-1884.jpg and is public domain, being its copyright expired. The right photo was personally taken by one of the authors. 

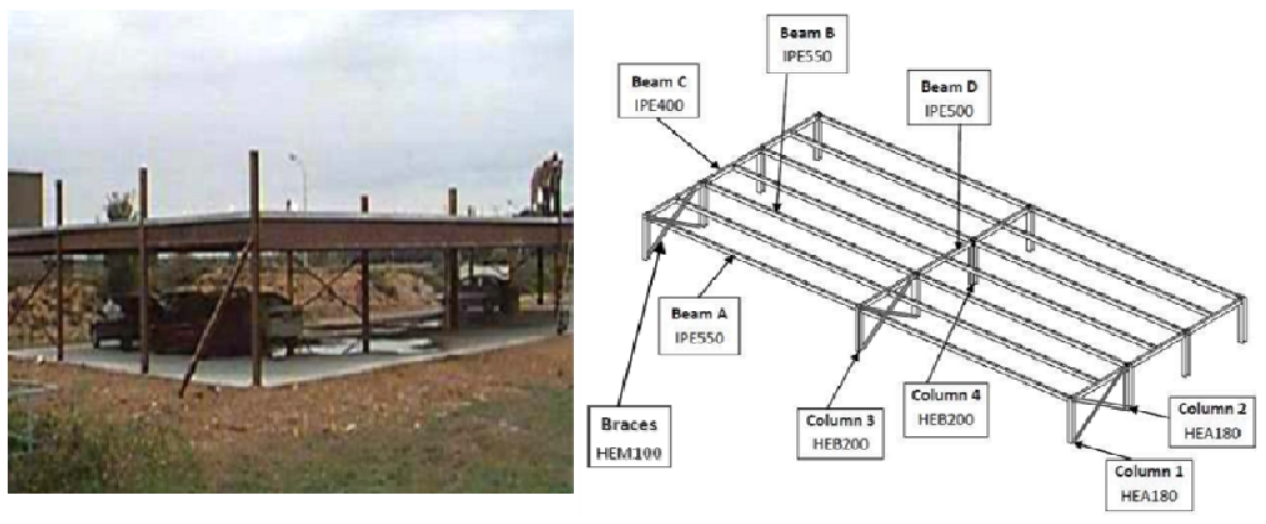

Fig. 3: Photo of the car park ${ }^{3}$ (left) and a sketch of its structural system (right)
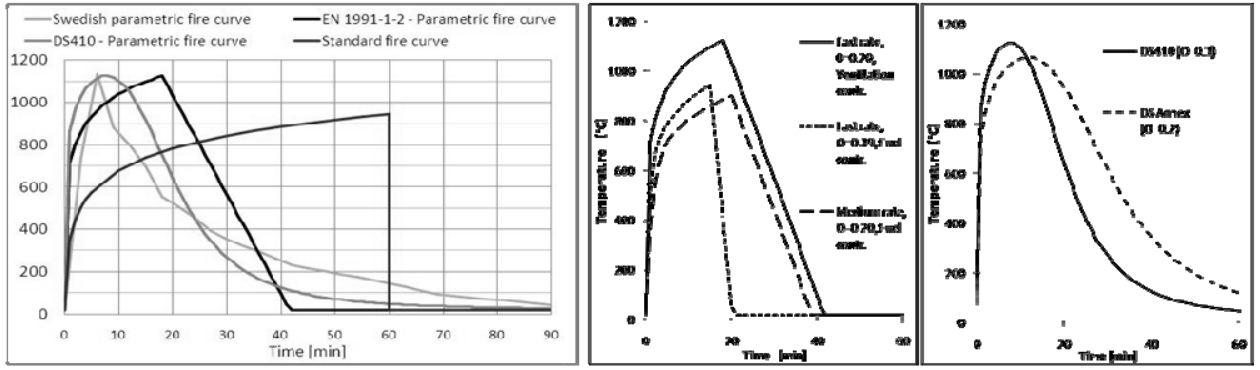

Fig. 4: Considered fire models (right) and effect of different assumption on the fire curves (right)

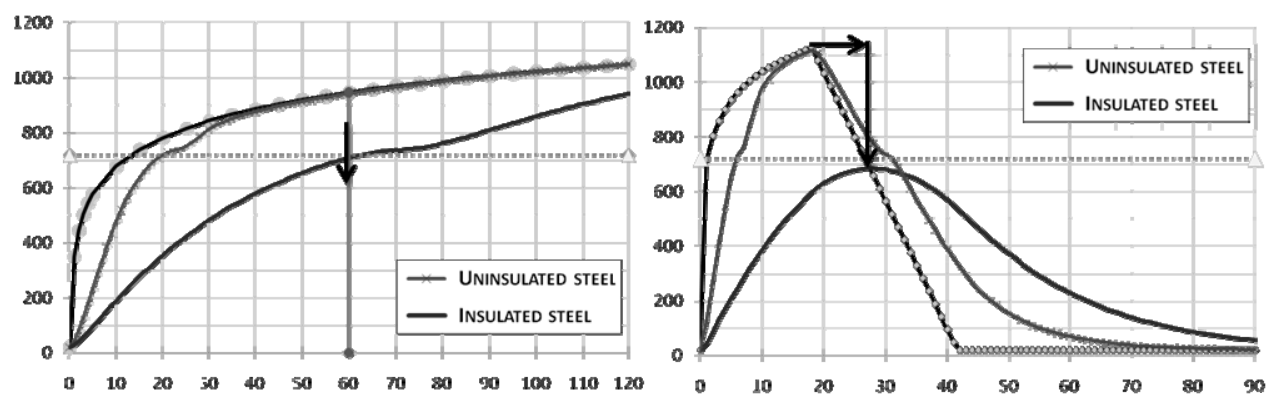

Fig. 5: Heating curve of a steel element for standard and EN parametric fire

\footnotetext{
${ }^{3}$ The source of the picture is the CTICM technical report on the structure (Joeux et al., 2001)
} 

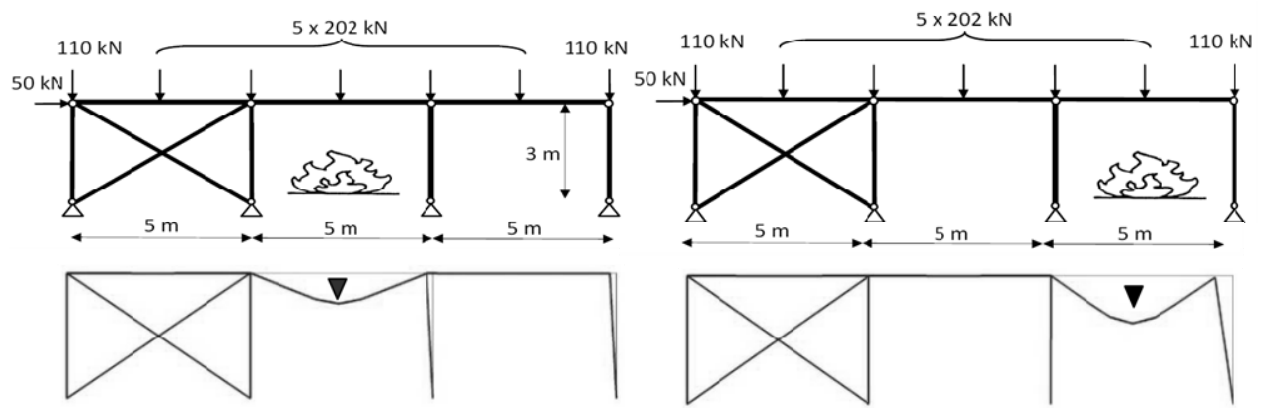

Fig. 6: Deformed configuration of the hinged frame under the assumption of two different fire scenarios: fire in the central (left) and side span (right)

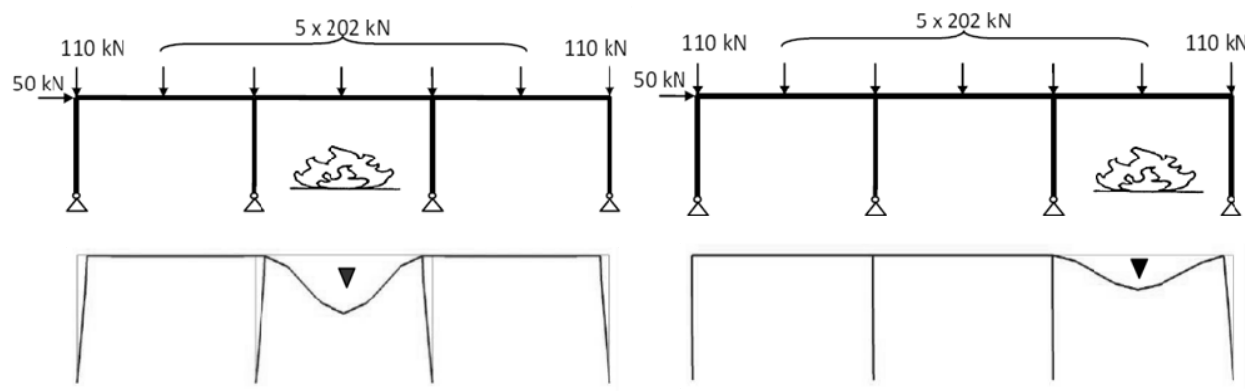

Fig. 7: Deformed configuration of the continuous frame under the assumption of two different fire scenarios: fire in the central (left) and side span (right)
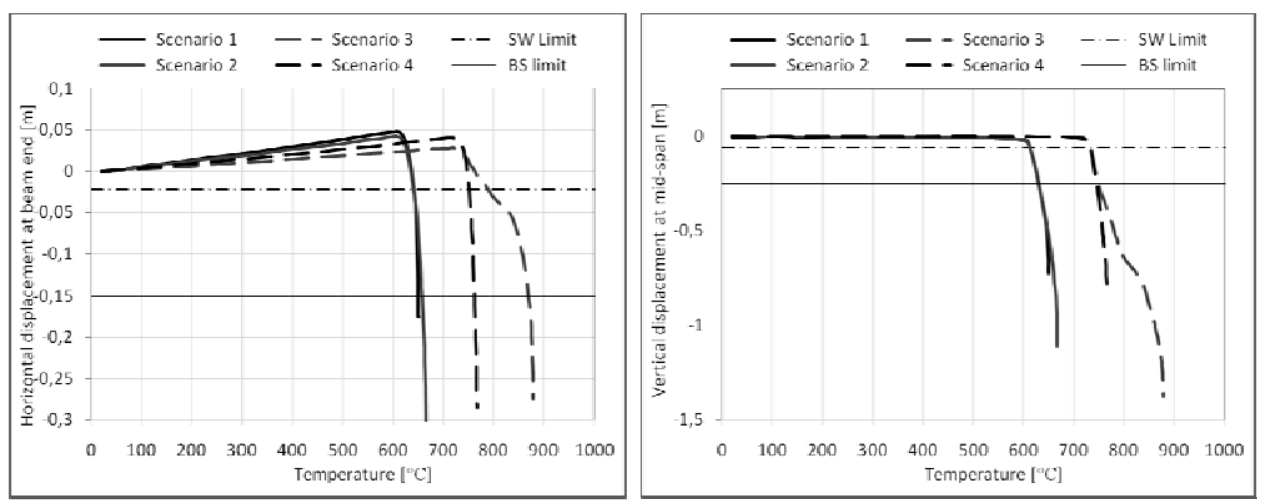

Fig. 8: Horizontal displacement of the beam end (left) and vertical displacements of beam mid-span for the two cases of fire in the central and side span for the hinged (scenario q and 2) and framed structure (scenario 3 and 4) 


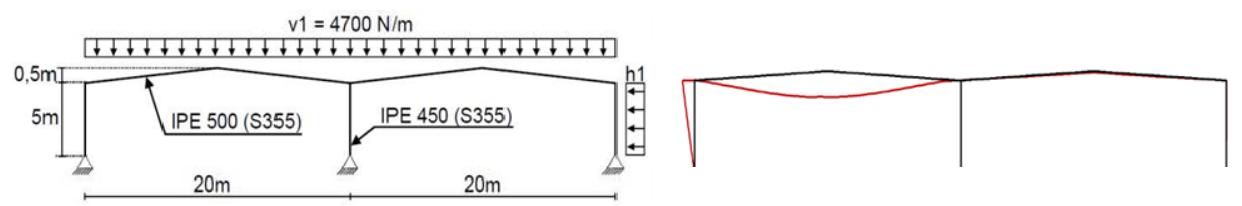

Fig. 9: Collapse modality of a two-span steel portal (Gentili et al., 2010)

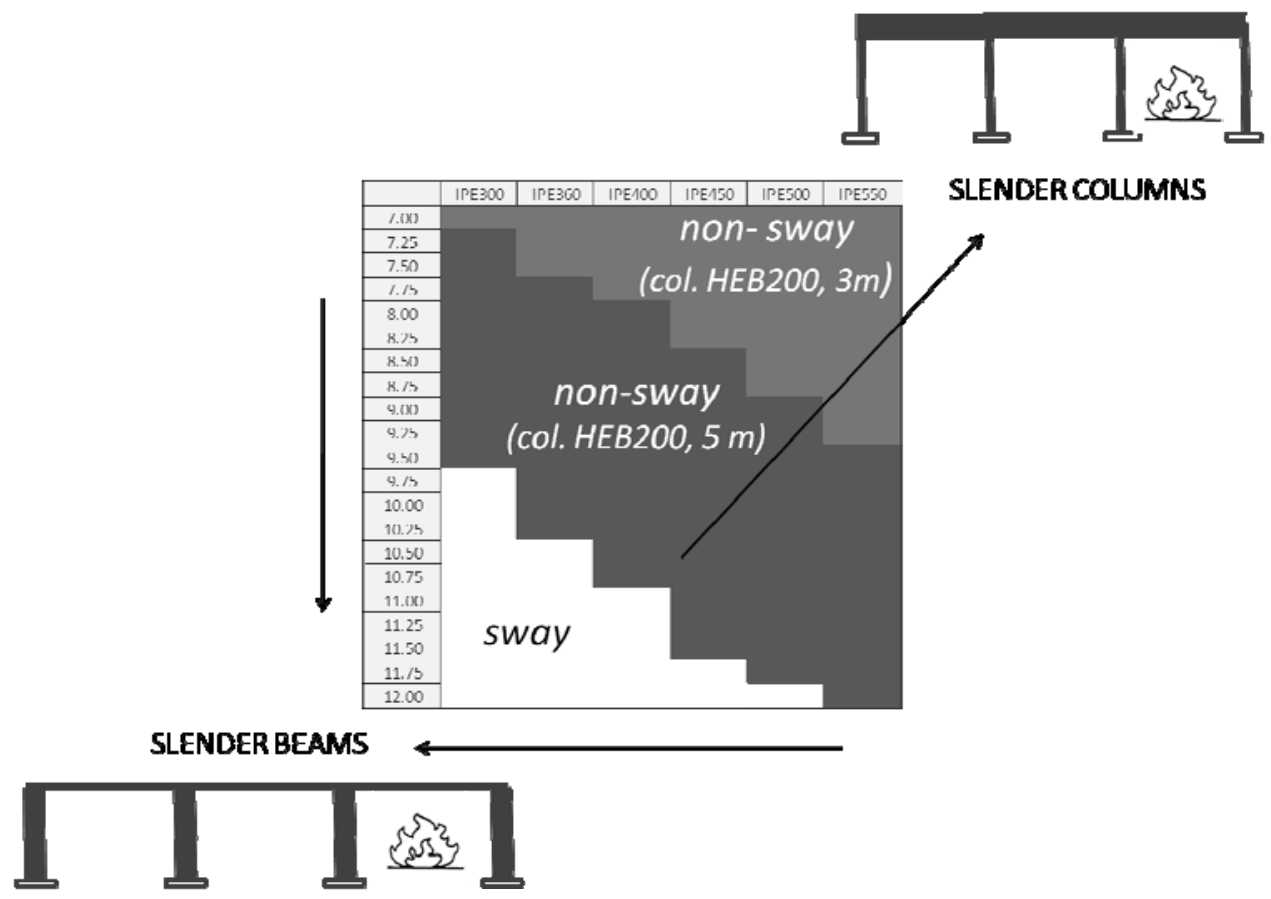

Fig. 10: Parametric study on the collapse modality of a three-span steel portal 
Tab. 1: Resistance classes for open-car parks in European countries (Pustorino et al., 2006)

\begin{tabular}{|c|c|c|c|c|c|c|c|}
\hline \multicolumn{4}{|c|}{ Structure } & \multicolumn{4}{c|}{ Resistance classes } \\
\hline Car park & floors & height & DE & FR & IT & ES $^{4}$ & UK \\
\hline open & 8 & 22 & 0 & $30-90$ & 90 & $90 / 60$ & 15 \\
\hline closed & 2 & -6 & 90 & $30-90$ & 90 & $90 / 60$ & $120-240^{5}$ \\
\hline
\end{tabular}

Tab. 2: Design fire load densities under different scenarios ${ }^{6}$

\begin{tabular}{|c|c|c|c|}
\hline Fire load density & Realistic scenario & Worst case scenario & Assumed scenario \\
\hline$\left[\mathrm{MJ} / \mathrm{m}^{2}\right]$ & 189 & 291 & 300 \\
\hline
\end{tabular}

Tab. 3: Values of relevant parameters defined in the Eurocodes and in the Danish National Annex

\begin{tabular}{|ll|c|c|}
\hline \multicolumn{2}{|l|}{ Different values of compartment fire parameters } & EN & DS \\
\hline Opening factor limit & {$\left[\mathrm{m}^{1 / 2}\right]$} & 0.20 & 0.30 \\
\hline Thermal inertia & {$\left[\mathrm{J} /\left(\mathrm{m}^{2} \mathrm{~s}^{1 / 2} \mathrm{~K}\right)\right]$} & 1730 & 1478 \\
\hline Fie load density & {$\left[\mathrm{MJ} / \mathrm{m}^{2}\right]$} & 291 & 300 \\
\hline
\end{tabular}

Tab. 4: Differences in safety factors for design values of actions (top) and reduction of the actions in case of ALS with reference to a floor slab of the car park (bottom)

\begin{tabular}{|c|c|c|c|c|c|c|}
\hline Regulation & \multicolumn{3}{|c|}{ EN } & \multicolumn{3}{c|}{ DS } \\
\hline Load combination & $\mathrm{G}$ & $\mathrm{Qk}, 1$ & $\mathrm{Qk}, \mathrm{i}$ & $\mathrm{G}$ & $\mathrm{Qk}, 1$ & $\mathrm{Qk}, \mathrm{i}$ \\
\hline ULS safety coeff. & 1.35 & 1.50 & $1.5 \cdot 0.7$ & 1.00 & 1.30 & 0.50 \\
\hline ALS safety coeff. & 1.00 & 0.60 & 0.20 & 1.00 & 1.00 & 0.50 \\
\hline
\end{tabular}

\begin{tabular}{|c|c|c|c|}
\hline Limit states & ULS & ALS & Ratio ALS/ULS \\
\hline EN & 8.49 & 4.55 & 0.54 \\
\hline DS & 7.15 & 6.25 & 0.87 \\
\hline
\end{tabular}

${ }^{4} \mathrm{R} 60$ applies if car park is isolated; other values can be used if advanced calculation methods are used

${ }^{5}$ R240 applies for compartment volumes greater than $7000 \mathrm{~m}^{3}$

${ }^{6}$ Realistic and worst case scenarios refer to different distributions of car types in the parking area, as according to the European classification of car and reported in (Joyeux et al. 2001). 
Tab. 5: Maximum and critical steel temperature of the car-park elements $\left[{ }^{\circ} \mathrm{C}\right]$

\begin{tabular}{|c|c|c|c|c|c|}
\hline & \multicolumn{3}{|c|}{ EN } & \multicolumn{2}{|c|}{$\mathrm{DS}$} \\
\cline { 2 - 6 } & $\mathrm{T}(\mathrm{R} 60)_{\text {st }}$ & $\mathrm{T}(\mathrm{par})_{\mathrm{st}}$ & $\mathrm{T}_{\text {crit }}$ & $\mathrm{T}_{\text {st }}$ & $\mathrm{T}_{\text {crit }}$ \\
\hline Column 1 & 940 & 1115 & 718 & 1115 & 651 \\
\hline Column 2 & 940 & 1115 & 637 & 1115 & 530 \\
\hline Column 3 & 938 & 1105 & 710 & 1079 & 634 \\
\hline Column 4 & 938 & 1105 & 629 & 1079 & 505 \\
\hline Beam A & 937 & 1099 & 685 & 1051 & 627 \\
\hline Beam B & 937 & 1099 & 594 & 1051 & 506 \\
\hline Beam C & 939 & 1110 & 621 & 1083 & 542 \\
\hline Beam D & 939 & 1105 & 592 & 1064 & 503 \\
\hline
\end{tabular}

Tab. 6: Necessary insulation layer ( $\mathrm{mm}$ of thickness for each element and total amount in $\mathrm{kg}$ )

\begin{tabular}{|c|c|c|c|c|}
\hline & $\begin{array}{c}\text { ISO834 } \\
\text { R60 }\end{array}$ & Parametric EN & Parametric DS & Parametric SW \\
\hline Column 1 & 10 & 7 & 6 & 3 \\
\hline Column 2 & 14 & 9 & 10 & 5 \\
\hline Column 3 & 7 & 5 & 5 & 2 \\
\hline Column 4 & 10 & 6 & 7 & 3 \\
\hline Beam A & 7 & 4 & 4 & 3 \\
\hline Beam B & 10 & 6 & 6 & 10 \\
\hline Beam C & 11 & 7 & 7 & 4 \\
\hline Beam D & 10 & 6 & 7 & 4 \\
\hline Total & 223 & 135 & 138 & 133 \\
\hline
\end{tabular}

Tab. 7: Comparison of the outcomes obtained by the prescriptive and PB investigations

\begin{tabular}{|c|c|c|c|}
\hline & $y_{c r}=\frac{L^{2}}{800 h}$ & $y_{c r}=\frac{L}{20}$ & $\begin{array}{c}\text { Prescriptive } \\
\text { verification }\end{array}$ \\
\hline Critical temperature & $612^{\circ} \mathrm{C}$ & $630^{\circ} \mathrm{C}$ & $592^{\circ} \mathrm{C}$ \\
\hline Critical time & $17 \mathrm{~min}$ & $18 \mathrm{~min}$ & $16 \mathrm{~min}$ \\
\hline
\end{tabular}


Tab. 8: Resistance properties of the two separate design solutions of the frame structure

\begin{tabular}{|c|c|c|}
\hline Collapse criterion & Hinged frame & Rigid frame \\
\hline$y_{c r}=\frac{L^{2}}{800 h}$ & $612^{\circ} \mathrm{C} / 17 \mathrm{~min}$ & $735^{\circ} \mathrm{C} / 25 \mathrm{~min}$ \\
\hline$y_{c r}=\frac{L}{20}$ & $630^{\circ} \mathrm{C} / 18 \mathrm{~min}$ & $750{ }^{\circ} \mathrm{C} / 26 \mathrm{~min}$ \\
\hline
\end{tabular}

